\title{
Instituciones de desequilibrio prestacional contenidas en los principios Unidroit aplicables a los negocios jurídicos nacionales
}

\author{
Recibido: 25 de julio de 2020 • Aprobado: 13 de noviembre de 2020 \\ https://doi.org/10.22395/ojum.v20n42a14
}

Gustavo Adolfo Beltrán Valencia

Universidad Autónoma Latinoamericana, Medellín, Colombia

gustavo.beltranva@unaula.edu.co

https://orcid.org/0000-0002-8650-7050

\section{RESUMEN}

El presente artículo tiene por objeto analizar la viabilidad jurídica de la aplicación de las instituciones jurídicas que velan por la justicia contractual en los negocios jurídicos nacionales dada la deficiente regulación que nuestro sistema legal privado posee frente a estas circunstancias de inequidad prestacional. Se analizan instituciones como la excesiva desproporción y la excesiva onerosidad (hardship), reguladas en instrumentos pertenecientes a la lex mercatoria o derecho comercial internacional, particularmente en los principios Unidroit. Para el cumplimiento de este objetivo se realiza un estudio comparativo entre las instituciones que velan por la justicia contractual contenidas en los principios Unidroit y las contenidas en el derecho positivo privado colombiano. Además, se hace un estudio de diversos casos abordados por la justicia arbitral nacional e internacional, así como por la jurisprudencia ordinaria, frente a la posibilidad de complementación e integración de las normas de los principios Unidroit en las legislaciones nacionales.

Todo lo anterior para concluir que es jurídicamente viable, a través del sistema de fuentes comercial doméstico y de los propósitos que el preámbulo de los principios Unidroit expresamente consagran, la aplicación directa a los negocios jurídicos comerciales nacionales de las figuras de la excesiva desproporción y de la excesiva onerosidad contenidas en este instrumento de derecho uniforme.

Palabras clave: lex mercatoria; principios Unidroit; excesiva onerosidad; excesiva desproporción; derecho privado. 


\title{
Institutions with an Unbalanced Provision Contained in the Unidroit Principles Applicable to National Legal Businesses
}

\begin{abstract}
The purpose of this article is to analyze the legal viability of the application of legal institutions that ensure contractual justice, such as excessive disproportion and excessive onerosity (hardship), regulated in instruments belonging to the lex mercatoria or international commercial law, particularly in the Unidroit Principles, in national legal businesses given the deficient regulation that our private legal system has in the face of these circumstances of unequal benefits; to fulfill this objective, a comparative study of the institutions that ensure contractual justice contained in the Principles with those contained in Colombian private positive law is carried out, and a study of various cases addressed by national and international arbitral justice, as well as by ordinary jurisprudence in the face of the possibility of complementation and integration of the norms of the Unidroit Principles in national legislation. All of the above to conclude that it is legally viable, through the domestic commercial source system and the purposes that the preamble of the Unidroit Principles expressly establishes, to directly apply the figures of excessive disproportion and of excessive burdens contained in this instrument of uniform law to national commercial legal businesses.

Keywords: international commercial law; lex mercatoria; Unidroit principles, excessive onerousness; excessive disproportion; private law.
\end{abstract}




\section{INTRODUCCIÓN}

El presente escrito deriva de la actividad académica e investigativa del autor como profesor titular del área de derecho mercantil durante los últimos quince años en diversas universidades del país.

Bajo una primera aproximación, es importante resaltar la incapacidad de los derechos locales codificados para darle solución adecuada a los conflictos derivados del comercio internacional. Así como la complejidad, y a veces contradicción, existente entre las normas de derecho internacional privado para entrar a determinar la ley sustancial aplicable a los asuntos mercantiles internacionales. Además, como manifiesta el profesor Fernández Rozas (2004): "las técnicas del DIPr basadas en las normas de conflicto se muestran a veces inadecuadas para regular las complejas cuestiones suscitadas en el ámbito del comercio internacional" (p. 55).

En palabras de Rodríguez (2009):

La lex mercatoria es una denominación usada para identificar a un conjunto normativo, con carácter supranacional, es decir, desligado del poder/capacidad de los Estados para dictar normas, con autonomía e independencia respecto a los ordenamientos estatales, y que es considerada la ley apropiada para la regulación de las relaciones económicas internacionales. (p. 307)

Por otro lado, Aljure (2011) se refiere a este fenómeno de la siguiente manera:

Como se sabe, esta no corresponde a normas que provengan de tratados internacionales o de normas nacionales, pues tiene su origen en principios y prácticas de los comerciantes que, por su general aceptación, son acogidas como lex contractus en los negocios internacionales. (p. 1)

Con respecto a su naturaleza jurídica, manifiesta Cadena (2006) que:

Su naturaleza jurídica se concibe como un conjunto histórico y actual de usos y prácticas comerciales consuetudinarias que mediante la aceptación coetánea de ciertas reglas de conducta por parte de los actores económicos internacionales, permite además de realizar diversas transacciones comerciales, resolver jurisdiccionalmente las controversias a través del arbitraje. (p. 23)

Así pues, este fenómeno jurídico se plantea como una respuesta jurídica satisfactoria a la regulación sustancial de los negocios jurídicos internacionales. Además, se entiende como un conjunto de normas jurídicas de carácter transnacional, que no provienen de la facultad legislativa de ningún Estado en particular. Más bien, provienen de la decantación y recopilación que diversas instituciones, privadas o intergubernamentales, han hecho de las distintas costumbres mercantiles observadas por los comerciantes en el tráfico mercantil internacional. Como también de los principios jurídicos que tienen un carácter común entre los diferentes sistemas jurídicos mundiales, todo lo cual pretende la uniformidad y armonización del derecho mercantil global. 
Si bien la lex mercatoria aglutina diversos instrumentos normativos, tales como: la Convención de Viena sobre los contratos de compraventa internacional de mercaderías (CISG), Los principios europeos de derecho de contratos (PECL), Las reglas y usos uniformes en materia de carta de crédito o crédito documentario; los Incoterms, entre otros. Todos ellos con vocación para reglar los negocios y contratos de índole internacional. También es cierto que algunos de los instrumentos configurativos de la lex mercatoria tienen como propósito expreso complementar y servir de modelo de inspiración configurativa para las legislaciones nacionales o locales.

En este orden de ideas, encontramos con este último propósito a los principios Unidroit, como instrumentos pertenecientes a la lex mercatoria en su faceta de derecho suave, ya que no emana de la voluntad soberana de un Estado en particular.

Resulta usual utilizar la denominación de derecho suave para referirse a todos aquellos actos que carecen de eficacia normativa y que son dictados organismos internacionales (Calderón, 2018).

Los principios Unidroit son un instrumento creado por el Instituto Internacional para la Unificación del Derecho Privado, con sede en Roma, de carácter intergubernamental. Este instituto tiene dentro de sus funciones la búsqueda de mecanismos y métodos para la armonización y coordinación del derecho privado entre los distintos países del orbe.

Dicho instituto acometió la tarea de recopilar o extraer, en un solo cuerpo normativo, los principios jurídicos comunes a los grandes sistemas legales, con miras a que esta normativa fuese aplicable como regulación uniforme a los contratos comerciales internacionales.

En estos términos se pronuncia la Corte Internacional de Arbitraje de la CPI en la Laudo Arbitral 7375 (1996), cuando aduce que:

Con respecto a la referencia a los principios de Unidroit, los árbitros de la mayoría creen que estos principios, preparados por un grupo de trabajo establecido en 1981 y compuesto por expertos y académicos líderes de todos los principales sistemas legales, contienen en esencia una reexpresión de esos "príncipes directeurs" que han disfrutado de la aceptación universal y, además, están en el corazón de las nociones más fundamentales que se han aplicado consistentemente en la práctica arbitral.

De tal suerte que, en el año 1994 aparece la primera versión de los principios Unidroit para los contratos comerciales internacionales, que luego serían actualizados. En el año 2001 se publica una segunda versión, una tercera en el año 2004 y las últimas versiones de los principios Unidroit datan de los años 2010 y 2016, respectivamente. Esta última versión atinente al tema de los contratos de larga duración. 
En un comienzo, y dado que se tratan de una modalidad de derecho suave, los principios son aplicables cuando las partes en virtud de su autonomía de la voluntad han optado por someter su contrato a la regulación contenida en los mismos.

Al respecto, el Centro de Arbitraje de México (CAM), en laudo arbitral de 30 de noviembre de 2006, señaló lo siguiente:

El derecho aplicable para resolver una controversia no tiene que ser derecho positivo mexicano, ni derecho positivo de jurisdicción alguna. Pueden ser normas que no teniendo dicho carácter las partes hayan escogido en ejercicio de su libertad contractual. [...] Al contemplar dicha posibilidad se deseó permitir la utilización de lo que se conoce doctrinalmente como el jus mercatorum o lex mercatoria. Si bien los ejemplos de dicho genero de normas abundan, el ejemplo más notorio de los mismos son precisamente los principios de la Unidroit.

A pesar de su vocación de internacionalidad, en su preámbulo, los principios Unidroit son claros en señalar que estos gozan gualmente de operatividad en diversas circunstancias. Entre ellas, cuando las partes hayan señalado que su contrato se regirá por la lex mercatoria o expresiones semejantes; cuando las partes no han escogido la ley aplicable a su contrato; cuando se trata de interpretar o complementar instrumentos internacionales de derecho uniforme, así como, ordenamientos jurídicos de orden nacional; y, adicionalmente, pueden servir como modelo para el desarrollo de los derechos nacionales e internacionales.

En cuanto al contenido de los principios Unidroit, estos tocan aspectos generales relativos a los contratos y las obligaciones, sin que se limiten a ningún tipo de contrato o figura jurídica en particular. A diferencia de otros instrumentos de lex mercatoria que sí se limitan, como sería el caso de la Convención de Viena (1980) sobre compraventa internacional de mercaderías (CISG), incorporada en Colombia, a través de la Ley 518 (1999) con vigencia a partir del 1 de agosto de 2002.

Frente a este instrumento, afirma Oviedo (2009): "Los principios Unidroit para los contratos comerciales internacionales, representan una nueva aproximación al Derecho de los negocios internacionales, y son un intento por remediar muchas de las deficiencias surgidas del Derecho aplicable a tales negocios" (p. 23).

De esta manera, los principios Unidroit, para los contratos comerciales internacionales, no se restringen únicamente al plano internacional, sino que paralelamente tienen dentro de sus objetivos que con base en ellos se pueda reconfigurar y perfeccionar las legislaciones mercantiles vernáculas.

A causa de lo planteado anteriormente, este escrito tiene como propósito traer a colación dos instituciones consagradas en los principios Unidroit. Estas pueden servir de inspiración para la transformación de nuestra legislación mercantil en aras de convertirse en un sistema jurídico que pueda responder, de forma más adecuada y justa, a la solución de gran cantidad de litigios y controversias de carácter comercial. 
El análisis propuesto resulta esencial en la medida en que algunas de nuestras instituciones mercantiles se encuentran totalmente rezagadas frente a los enfoques jurídicos internacionales. Esto se debe a la ausencia de regulación expresa por parte de nuestra ley mercantil frente a ciertas materias contractuales. Además, es en virtud de la remisión que hace el artículo 822 del Código de Comercio (1971), a nuestro Código Civil (1873) decimonónico de inspiración romana y francesa, que dichas instituciones tienen aplicación, corolario por lo cual terminan siendo no ajustadas a las problemáticas mercantiles actuales.

En esta medida, la complejidad de los problemas que padece la sociedad contemporánea necesita de sistemas normativos adaptables y eficaces para su resolución, como bien manifiestan Rocha y Da Luz (2009): "La norma policontextual se encuentra formada por la introducción de una ruptura histórica de la sociedad hipercompleja y su reorganización espacio-temporal por la globalización" (p.115)!

En relación con lo anterior, este trabajo acometerá bajo el prisma de los principios Unidroit y el análisis de las figuras de la excesiva desproporción y de la excesiva onerosidad (hardship). Para esto, se hará un estudio comparativo de estas instituciones con las contenidas en el derecho positivo privado colombiano. En este sentido, se indagará sobre diversos casos abordados por la justicia arbitral nacional e internacional, como también por la jurisprudencia ordinaria relativa a la posibilidad de complementación e integración de las normas de los principios Unidroit a las legislaciones domésticas. De esta manera, se podrá establecer la viabilidad jurídica de la aplicación directa de estas instituciones contenidas en los principios Unidroit a los negocios jurídicos comerciales nacionales.

\section{EXCESIVA DESPROPORCIÓN}

Nuestro sistema jurídico de derecho privado consagra la figura de la excesiva desproporción, con el nombre de lesión enorme o de lesión grave en los siguientes eventos:

En el contrato de compraventa civil de bienes inmuebles, artículos 1946 y 1947 del Código Civil (1873), lesión enorme que, por remisión del artículo 822 del Código de Comercio (1971) a la legislación civil, es aplicable también a los negocios de compraventa mercantil sobre bienes inmuebles.

Permuta civil sobre bienes inmuebles de conformidad con la remisión que el artículo 1958 del Código Civil (1873) hace al contrato de compraventa civil, de conformidad con la remisión del artículo 822 del Código de Comercio (1971) a la legislación civil. Aquí también aplica la lesión enorme en las permutas mercantiles sobre bienes inmuebles.

En las particiones se concede acción rescisoria por causa de lesión en el artículo 1405 inciso segundo del Código Civil (1873).

Original: "The polycontextural law is formed by the introduction of a historical ruptura of the hypercomplex society and its spacio-temporal reorganization by the globalization". 
En la aceptación de la herencia artículo 1291 del Código Civil (1873).

En el mutuo y la anticresis civil en los artículos 2231 y 2466 del Código Civil (1873).

En el mutuo mercantil artículo 884 del Código de Comercio (1971).

En el derecho real de hipoteca artículo 2455 del Código Civil (1873), que por remisión del artículo 822 del Código de Comercio (1971) también aplica a la hipoteca mercantil.

En la cláusula penal, tanto civil como mercantil, artículo 1601 del Código Civil (1873) y 867 del Código de Comercio (1971), respectivamente.

Ahora bien, la excesiva desproporción consiste en un desequilibrio, manifiesto e inequitativo, que se presenta al momento de la celebración de un contrato o negocio jurídico. De esta manera, se ve afectada la conmutatividad de las prestaciones derivadas del contrato, bien porque alguna de las prestaciones sea fehacientemente inocua o excesivamente onerosa.

La lesión enorme es pues, una institución a la que subyace un cuestionamiento a la manera como proceden los hombres en sus negocios, en la que además, palpita una clara tensión entre los principios de justicia y de seguridad jurídica, toda vez que, por una parte, el derecho procura que en los negocios jurídicos [...] principalmente en los conmutativos o interesados exista una relativa correspondencia económica entre las obligaciones de las partes y, por otra, propende al mismo tiempo, a la estabilidad en las relaciones de intercambio. (Álvarez, 2009, p. 602)

Por otro lado, en los principios Unidroit (2010), la excesiva desproporción se encuentra consagrada en el artículo 3.2.7 así:

(Excesiva desproporción)

(1) Una parte puede anular el contrato o cualquiera de sus cláusulas si en el momento de su celebración el contrato o alguna de sus cláusulas otorgan a la otra parte una ventaja excesiva. A tal efecto, se deben tener en cuenta, entre otros, los siguientes factores:

(a) que la otra parte se haya aprovechado injustificadamente de la dependencia, aflicción económica o necesidades apremiantes de la otra parte, o de su falta de previsión, ignorancia, inexperiencia o falta de habilidad en la negociación; y

(b) la naturaleza y finalidad del contrato.

(2) A petición de la parte legitimada para anular el contrato, el tribunal podrá adaptar el contrato o la cláusula en cuestión, a fin de ajustarlos a criterios comerciales razonables de lealtad negocial.

(3) El tribunal también podrá adaptar el contrato o la cláusula en cuestión, a petición de la parte que recibió la notificación de la anulación, siempre y cuando dicha parte haga saber su decisión a la otra inmediatamente, y, en todo caso, antes 
de que ésta [sic] obre razonablemente de conformidad con su voluntad de anular el contrato. Se aplicará, por consiguiente, el párrafo (2) del Artículo 3.10.

Frente a la excesiva desproporción el Tribunal de Distrito de los Estados Unidos, SD Florida (2007) afirma que:

En el caso número 9029 de la CPI, el tribunal con sede en roma discutió la aplicación de la gran disparidad. El tribunal declaró: aquí deben de existir dos presuposiciones para que el principio de dificultad grave sea aplicable, a saber, que debe haber una disparidad grave entre los derechos y las obligaciones recíprocos de las partes que otorga una ventaja excesiva a una parte y que la ventaja excesiva debe ser injusta, es decir que una parte debe de haber aprovechado excesivamente una dependencia en un estado de necesidad económica, necesidades urgentes o falta de previsión, ignorancia, inexperiencia o la incapacidad de la otra parte para llevar a cabo las negociaciones. (pp. 10-11)

De acuerdo con lo anterior, se pueden mencionar las siguientes diferencias entre la lesión enorme de nuestro sistema jurídico privado y la excesiva desproporción del instrumento de lex mercatoria:

Los casos en que la lesión enorme tiene operancia en nuestra legislación son de carácter taxativo, mientras que la excesiva desproporción tiene cabida en cualquier contrato en el que se presente una ventaja excesiva a favor de alguna de las partes.

En materia de compraventa y permuta, en nuestra legislación de derecho privado, la lesión enorme recae únicamente sobre bienes inmuebles, mientras que, en materia de excesiva desproporción, no se distingue. Es decir, que esta puede recaer tanto sobre bienes muebles como inmuebles, como sobre cosas corporales e incorporales.

Los presupuestos para que se esté en presencia de la lesión enorme en nuestra legislación son de carácter objetivo, pues atienden a criterios aritméticos para establecer el desequilibrio contractual. Así, por ejemplo, el artículo 1947 del Código Civil (1873), en materia de compraventa sobre bienes inmuebles, señala que habrá lesión enorme para el vendedor cuando el precio que recibe es inferior a la mitad del justo precio de la cosa que vende, y para el comprador cuando el justo precio de la cosa que compra es inferior a la mitad del precio que paga por ella.

Por otro lado, tratándose de los principios Unidroit, el criterio para determinar la existencia de lesión enorme es de carácter mixto, pues aparte de la excesiva desproporción aritmética (criterio objetivo). En este sentido, se tienen que tener en cuenta también criterios subjetivos, los cuales tienen que ver con la situación de inferioridad del sujeto lesionado bien sea por su dependencia; aflicción o necesidades económicas; su falta de previsión, ignorancia o inexperiencia; o por el correlativo aprovechamiento injustificado del lesionante de esta inferioridad.

En materia de lesión enorme, nuestro Código Civil (1873) consagra, como consecuencia de la misma, que el contrato se rescinda, esto es, que se declare relativamente nulo. Por otro lado, si bien en los principios Unidroit también la excesiva desproporción trae aparejada la posibilidad de anular el contrato, establece 
adicionalmente un remedio contractual acorde con el principio de la conservación del negocio jurídico. Esto consistente en que a petición tanto de la parte afectada, como del lesionante, el juez pueda adaptarlo a su justo equilibrio económico.

Es a partir de estas diferencias que podemos plantear que la regulación de la excesiva desproporción, en el instrumento internacional de derecho uniforme, es mucho más consecuente con un orden jurídico más justo. Esto se debe a que muchas figuras mercantiles actuales pueden ser utilizadas de forma abusiva por compañías internacionales o nacionales con socios extranjeros -con un gran poder económico y financiero dentro de los mercados-. De esta manera, son utilizadas como instrumentos para aprovechar la situación de desventaja económica o las necesidades apremiantes de los pequeños y medianos empresarios, para celebrar contratos con ellos, con un claro contenido económico desigual.

En este orden de ideas, los frentes más preocupantes sobre los cuales podrían abusar dichas corporaciones, sería el de la adquisición desequilibrada de los bienes mercantiles nacionales. Esto sería un grave perjuicio para la empresa y la industria local, entre otras razones, porque las utilidades de la explotación de estas actividades económicas tendrían como destinatarios finales a las grandes multinacionales o accionistas extranjeros.

Así, por ejemplo, se pueden presentar escenarios de adquisiciones de grandes paquetes accionarios, por parte de sociedades extranjeras, del capital de sociedades colombianas. Esto con el fin de tomar su control y convertirse en matrices, adquisición que, en eventuales circunstancias de crisis económica, se podría dar a precios completamente irrisorios. Así mismo, frente a sociedades anónimas abiertas listadas en la Bolsa de valores de Colombia, se pueden configurar ofertas públicas de adquisición de carácter hostil. De la misma manera, se pueden celebrar reformas estatuarias de fusión, o escisión, en donde los términos de transferencia patrimonial, entre las sociedades intervinientes y de intercambio accionario entre los socios, se presente en condiciones claramente desequilibradas.

Igualmente, por el lado de los establecimientos de comercio, se pueden manifestar bajo circunstancias de crisis económica, enajenaciones de almacenes, oficinas, fabricas, sucursales, agencias, entre otros, a diversos títulos. Llámese compraventa, permuta, aporte a sociedades, daciones en pago, entre otros, cuyos precios sean injustamente desproporcionados, o inclusive enajenaciones globales de activos en estas mismas condiciones.

De la misma manera, se pueden perfeccionar contratos de transferencia de tecnología, tales como, franquicias, cesiones o licencias de bienes pertenecientes a la propiedad industrial-como patentes, diseños industriales, marcas, denominaciones de origen, nombres comerciales, enseñas, know how, secretos industriales o empresariales, entre otras- con contraprestaciones ostensiblemente desequilibradas. 
Para el caso de los títulos de valores, una crisis económica podría eventualmente desembocar en enajenaciones de carteras a precios insignificantes, a través de operaciones de factoring, en perjuicio de los titulares de estas carteras, como consecuencia del ansia de estos por obtener liquidez inmediata.

En síntesis, como se puede apreciar, es muy factible que todas estas situaciones ocurran en épocas de crisis económicas y empresariales. Por esta razón, la institución que mejor responde a la salvaguarda de la justicia contractual en estas circunstancias, es la de la excesiva desproporción regulada en los principios Unidroit. Esto se debe a que es una institución aplicable a todo tipo de contrato, sea típico o atípico; no se restringe únicamente a los bienes inmuebles, sino que cabrían, inclusive, los negocios jurídicos que recayeran sobre cosas muebles, corporales o incorporales. Además, posibilitan la realización del principio de la conservación contractual, en la medida en que el juzgador puede ajustarlo para evitar su declaración de nulidad.

\section{EXCESIVA ONEROSIDAD (HARDSHIP):}

Nuestra legislación comercial consagró en el artículo 868 del Código de Comercio la denominada teoría de la imprevisión, la cual recogió de la jurisprudencia del derecho administrativo francés de principios del siglo XX. Esta institución tiene unos rasgos muy similares a la excesiva onerosidad o hardship contenida en los principios Unidroit en los artículos 6.2.2 y 6.2.3.

En el artículo 868 del Código de Comercio (1971) se afirma que:

Cuando circunstancias extraordinarias, imprevistas o imprevisibles, posteriores a la celebración de un contrato de ejecución sucesiva, periódica o diferida, alteren o agraven, la prestación de futuro cumplimiento a cargo de una de las partes, en grado tal que le resulte excesivamente onerosa, podrá pedir su revisión.

El juez procederá a examinar las circunstancias que hayan alterado las bases del contrato y ordenará, si ello es posible, los reajustes que la equidad indique; en caso contrario, el juez decretará la terminación del contrato.

Esta regla no aplicara a los contratos aleatorios ni a los de ejecución instantánea.

Por otra parte, el artículo 6.2.2 de los principios Unidroit (2010) manifiesta que:

(Definición de la "excesiva onerosidad" (hardship))

Hay "excesiva onerosidad" (hardship) cuando el equilibrio del contrato es alterado de modo fundamental por el acontecimiento de ciertos eventos, bien porque el costo de la prestación a cargo de una de las partes se ha incrementado, o porque el valor de la prestación que una parte recibe ha disminuido, y:

a) dichos eventos acontecen o llegan a ser conocidos por la parte en desventaja después de la celebración del contrato; 
b) los eventos no pudieron ser razonablemente tenidos en cuenta por la parte en desventaja en el momento de celebrarse el contrato;

c) los eventos escapan al control de la parte en desventaja; y

d) el riesgo de tales eventos no fue asumido por la parte en desventaja. (p. 21)

Por otro lado, el artículo 6.2.3. de los principios Unidroit (2010), refiriéndose a sus efectos, señala que:

(Efectos de la "excesiva onerosidad" (hardship))

(1) En caso de "excesiva onerosidad" (hardship), la parte en desventaja puede reclamar la renegociación del contrato. Tal reclamo deberá formularse sin demora injustificada, con indicación de los fundamentos en los que se basa.

(2) El reclamo de renegociación no autoriza por sí mismo a la parte en desventaja para suspender el cumplimiento.

(3) En caso de no llegarse a un acuerdo dentro de un tiempo prudencial, cualquiera de las partes puede acudir a un tribunal.

(4) Si el tribunal determina que se presenta una situación de "excesiva onerosidad" (hardship), y siempre que lo considere razonable, podrá:

a) resolver el contrato en fecha y condiciones a ser fijadas; o

b) adaptar el contrato con miras a restablecer su equilibrio. (p. 21)

Ahora bien, es claro que en materia contractual en la mayoría de los sistemas legales, tiene plena injerencia el principio del pacta sunt servanda. Este principio concede seguridad jurídica a los negocios que se desarrollan en el tráfico jurídico mercantil, en la medida en que las partes contratantes se someten a sus estipulaciones contractuales, sin que les sea dable sustraerse de las mismas con posterioridad a la celebración del contrato, salvo expresos motivos legales o por mutuo consentimiento de las mismas. Todo esto en aras del mantenimiento del orden público económico.

Sin embargo, también hay que afirmar que el principio del pacta sunt servanda no es de carácter absoluto, pues al lado de este se encuentra otro principio que lo atempera y lo morigera. Este es el del rebus sic stantibus, en virtud del cual, los términos de los contratos se deben de observar, siempre y cuando no se presente una alteración grave en las circunstancias que lo rodean.

Ya en su espectro social, resulta indispensable que las prestaciones se cumplan de acuerdo a lo pactado, pero aparece extraño a la figura misma pensar que ello deba ser así cuando la prestación que ha sido diferida en el tiempo ha sufrido una variación imprevisible que la hace excesivamente onerosa para una de las partes. En este sentido vale precisar que no parece existir un claro enfrentamiento entre los principios pacta sunt servanda y rebus sic stantibus. (Franco, 2013, p. 449) 
Así las cosas, los institutos de la teoría de la imprevisión y de la excesiva onerosidad encuentran sustento en el principio del rebus sic stantibus. De esta manera, lo que se busca con ellos es remediar el desequilibrio contractual que se presenta cuando por una situación imprevista, extraordinaria, y posterior a la celebración de la convención, las prestaciones de las partes pierden su conmutatividad, tornándose extremadamente oneroso el cumplimiento de la prestación para una de ellas.

Con relación al principio del rebus sic stantibus, manifiesta el Tribunal Supremo español:

La aplicación de la rebus atiende a la quiebra o frustración de la conmutatividad y onerosidad contractual sobre la que se diseñó el resultado práctico querido por las partes, se valora la ruptura del equilibrio contractual por la onerosidad sobrevenida de la relación negociada celebrada. (Sentencia 333/14, 2014)

De esta manera, la teleología de ambos institutos es la de reestablecer, con fundamento en la equidad, el equilibrio contractual desdibujado en clara sintonía con el principio de la conservación contractual.

Sin embargo, entre la teoría de la imprevisión de la legislación comercial patria y la excesiva onerosidad del instrumento de lex mercatoria Unidroit, podemos plantear las siguientes diferencias en su dinámica de aplicación:

La excesiva onerosidad (hardship), tiene aplicación -tal como se desprende de su regulación, artículo 6.2.2 inciso primero- cuando se presenta un desequilibrio contractual, tanto por exceso como por defecto. Es decir, tanto si la prestación de una de las partes se torna excesivamente onerosa para su cumplimiento, como cuando el valor de la prestación que una parte recibe ha disminuido considerablemente.Todo esto, al mismo tiempo que la teoría de la imprevisión del artículo 868 del Código de Comercio (1971) solo tiene cabida cuando la prestación de una de las partes se vuelve excesivamente onerosa.

La teoría de la imprevisión se admite únicamente en los contratos de ejecución sucesiva, periódica o diferida, mientras que la figura de la excesiva onerosidad (hardship) no la distingue. De ahí que esta pueda ser aplicable no solamente a los contratos de tracto sucesivo, sino también a los contratos de ejecución instantánea, aunque las prestaciones no estén diferidas en el tiempo, e inclusive a contratos unilaterales y gratuitos.

Al respecto, Oviedo (2009) manifiesta que:

En el comentario 5 al artículo 6.2.2, se señala: "La excesiva onerosidad (hardship) suele tener importancia en los contratos de larga duración" Aunque en este artículo no se excluye expresamente la posibilidad de que la excesiva onerosidad (hardship) se aplique a otra clase de contratos. (p. 270)

- Tratándose de la teoría de la imprevisión, cuando ocurre el desequilibrio económico del contrato, con ocasión de las circunstancias extraordinarias, imprevistas o imprevisibles, y posteriores a la celebración del contrato, dice la norma 
que la parte afectada puede acudir directamente al juez para que este lo revise. Además, si es del caso, lo ajuste conforme a la equidad o, si esto no es posible, lo dé por terminado, en otras palabras, la norma llama en primera instancia al juez para que adapte el contrato.

Por otro lado, tratándose de la excesiva onerosidad (hardship), a quienes primero llama la norma para que intenten ajustar su contrato, es a los directamente involucrados, esto es, a las partes contratantes. En este sentido, se faculta a la parte afectada con el desequilibrio prestacional para que reclame la renegociación del contrato con su contraparte, y solo si, en un tiempo prudencial, dicha renegociación no llega a feliz término se puede acudir ante las instancias judiciales.

Esta última posición resulta mucho más coherente, ya que son las partes involucradas en el contrato las que mejor conocen los términos de su negociación y la finalidad que persiguen con su celebración.

Al respecto, Mantilla y Ternera (2008) manifiestan que:

Los contratos son acuerdos celebrados entre las partes; a través de ellos, los contratantes regulan sus relaciones económicas específicas, satisfacen sus necesidades particulares y reglamentan, de forma determinada, la distribución de las ganancias o de las pérdidas de la operación económica. Por consiguiente, toda modificación que dichos acuerdos vayan a sufrir debe provenir, en primera instancia de los contratantes mismos; y si el Estado se encuentra interesado en intervenir en las reglamentaciones privadas de las operaciones económicas de los particulares, para adaptarlas a los cambios de las circunstancias económicas, la primera vía que debe seguir es la de facultar al juez para que presione a las partes e induzca así los reajustes. (p. 322)

Por su parte, Polidura (2017) manifiesta que:

Varias legislaciones extranjeras y trabajos académicos encaminados a la armonización de los distintos ordenamientos, por su parte, se refieren de manera expresa al deber de los contratantes, y fundamentalmente de la parte que no padece los efectos de la excesiva onerosidad, de renegociar las condiciones del contrato. Precisamente en este sentido, el artículo 6.2.3 de los principios Unidroit. (p. 20)

En la teoría de la imprevisión quien está legitimado para acudir a la vía jurisdiccional, para que se revise el contrato, es únicamente la parte afectada con el desequilibrio. Por el contrario, tratándose de la excesiva onerosidad (hardship), todas las partes contractuales se encuentran legitimadas para acudir ante los tribunales. De esta manera, no solo la parte afectada, y que pretende la adaptación del contrato, sino también la parte que se opone a dicho reajuste está facultada para acudir ante el juez.

- Las circunstancias que posibilitan la aplicación de la teoría de la imprevisión se deben de presentar con posterioridad a la celebración del contrato. Sin embargo, tratándose de la excesiva onerosidad (hardship), los hechos que pueden dar lugar a su aplicación pueden haber ocurrido antes de la celebración del contrato, pero ser conocidos por la parte afectada luego de su perfeccionamiento. 
Por lo demás, ambas instituciones son esencialmente idénticas en cuanto a sus efectos. Se resalta, conforme a lo esgrimido anteriormente, la regulación establecida en los principios Unidroit resulta mucho más coherente para hacer frente a la crisis empresarial actual.

Al respecto, son muy oportunas las palabras de Morles (2010):

los principios de Unidroit ejercen, sin duda, una gran influencia en la divulgación de los supuestos de procedencia y en los efectos de las situaciones de cambio de circunstancias. Los principios de Unidroit se han convertido en la nueva lingua franca del derecho internacional de los contratos, o, como también se postula, en un nuevo Usus modernus Pandectarum. (p. 378)

\section{VIABILIDAD DE APLICACIÓN DE LOS REMEDIOS CONTRACTUALES DE EXCESIVA DESPROPORCIÓN $Y$ EXCESIVA ONEROSIDAD CONTENIDOS EN LOS PRINCIPIOS UNIDROIT EN LOS CONTRATOS COMERCIALES DOMÉSTICOS:}

A continuación, nos vamos a remitir al sistema de fuentes mercantil para responder al interrogante sobre la posibilidad de la aplicación de instituciones contenidas en los principios Unidroit en el sistema legal colombiano, y sobre los contratos comerciales que carezcan de cualquier factor de internacionalidad.

Conforme a lo anterior, y bajo una primera aproximación, los principios Unidroit admitirían su aplicación en Colombia, inclusive para regir contratos nacionales, a través de la vía de la estipulación contractual. Esto, porque en nuestra jerarquía de fuentes formales las estipulaciones contractuales únicamente se encuentran subordinadas a las leyes comerciales de carácter imperativo. Es decir, a aquellas establecidas para la salvaguarda del orden público económico, pero en lo demás, dichas estipulaciones se encuentran por encima y gozan de preferencia en su aplicación a las leyes comerciales supletivas, a las costumbres mercantiles y a la ley civil no invocada expresamente por nuestra legislación mercantil.

Al respecto, afirman Vásquez y Vidal (2018): "La lex mercatoria es aplicable directamente a partir de la voluntad de las partes en sus contratos, sin requerir un reconocimiento previo por el Estado" (p. 240).

El artículo 4 del Código de Comercio (1971) corrobora lo anterior cuando afirma que: "Las estipulaciones de los contratos válidamente celebrados preferirán a las normas legales supletivas y a las costumbres mercantiles".

De esta manera, los principios Unidroit y, particularmente, figuras allí contenidas, como la excesiva onerosidad (hardship), antes que contravenir, son instituciones que se ajustan plenamente a los fundamentos políticos y económicos de nuestro Estado social de derecho, así como al orden jurídico económico que este pretende sustentar. De ahí que un pacto contractual consistente, en caso de que se presenten 
desequilibrios sustanciales en las prestaciones con posterioridad a la celebración del negocio y, como consecuencia de circunstancias extraordinarias e imprevisibles, sea remediado a la luz de las normas Unidroit. Esto en lugar de la aplicación de la teoría de la imprevisión del Código de Comercio (1971), por considerar las partes que aquella normativa internacional resulta mucho más adecuada y garantista.

Se opta entonces, por entender como único límite a la autonomía de la voluntad, el constituido por el orden público, percibido como un concepto amplio, genérico o totalizador. El mismo incluye, no solamente a las leyes imperativas (dentro de las cuales están las normas constitucionales), sino otros elementos como los fundamentos político-económicos de la sociedad (la protección de la parte débil, la familia como núcleo esencial de la sociedad, la persona y su integridad como interés fundamental, la represión de los comportamientos ilícitos); los valores morales de la comunidad (las buenas costumbres, la buena fe, el no abuso del derecho, la razonabilidad de las acciones, etc.), entre otros. (Espinosa, 2010, p. 515)

Lo anterior, se vislumbra con mucha mayor claridad si llegamos inclusive al punto extremo de considerar que nuestro sistema comercial es de carácter enteramente supletivo. Tal como afirma León (2014) refiriéndose a Zapata de Arbeláez: "Esta posición es asumida igualmente por Zapata de Arbeláez, para quien la legislación mercantil colombiana es netamente dispositiva, al igual que la regla de conflicto que lo regula" (p. 61).

Ahora bien, podemos plantear una segunda aproximación a la aplicación de los principios Unidroit en los actos jurídicos internos, para lo cual debemos partir de la base de que su naturaleza jurídica se constituye en verdaderas costumbres mercantiles de carácter internacional y que, como tal, hacen parte de la llamada nueva lex mercatoria.

Al respecto, señala Tobar (2020), refiriéndose a la Sentencia 70072362940/17 (2017) de la Corte de Apelaciones del Estado de Rio Grande del Sur (Brasil):

En su decisión, el tribunal de apelación indicó que en tanto el contrato tenía varios puntos de contacto con más de un Estado, la regla según la cual el contrato se rige por la ley del lugar de su celebración (que para el caso concreto seria la ley danesa), debía ser ignorada en favor de un enfoque más flexible que condujera a la aplicación de la CISG y los principios Unidroit como una expresión de la llamada "nueva lex mercatoria". (p. 149)

En términos similares, manifiesta la Cámara de Comercio de Bogotá en la Laudo Arbitral (2002):

En igual sentido se pronuncian las reglas de Unidroit (art. 7.3.1, N 1), que en su condición de principios internacionales están orientados al derecho comercial y constituyen, cada vez más, como expresión eximia de la llamada "lex mercatoria", un punto de referencia de primer orden para el estudio de la evolución moderna del derecho mercantil. 
En este orden de ideas, es indudable que el fenómeno de la lex mercatoria goza de todos los atributos para ser considerado como una costumbre mercantil. Sobre todo, si tenemos en cuenta este fenómeno como un conjunto de prácticas uniformes, públicas y reiteradas, frente a las cuales existe una conciencia de obligatoriedad. Prácticas que, además, han sido decantadas y observadas por los operadores del comercio internacional en sus transacciones internacionales.

Al respecto, Toro (2019) manifiesta que:

Por lo tanto, y evocando la construcción medieval, el legislador colombiano retoma el concepto de prácticas reiteradas con conciencia de obligatoriedad como un sinónimo de la lex mercatoria [...], el denominador de costumbre mercantil internacional comprende la moderna lex mercatoria desarrollada desde comienzos del siglo XX. Esta identifica las practicas comunes a un derecho comercial - y un derecho del comercio internacional-globalizado y transnacional. (p. 91)

De acuerdo con este razonamiento, si asumimos que los principios Unidroit son un instrumento que pertenece a la nueva lex mercatoria, consecuentemente dichos principios son, a su vez, verdaderas costumbres mercantiles.

Bajo estas consideraciones, encontramos pronunciamientos arbitrales, por ejemplo, en la base de datos Unilex, frente a una Laudo Arbitral (2016) proferida por la Comisión de Arbitraje comercial y Económico Internacional de China (Cietac), se afirma que:

En vista de esta situación, el Tribunal Arbitral, basándose en el párrafo 49(1) de las reglas de Arbitraje de Cietac 2015, según el cual "El tribunal arbitral emitirá de manera independiente e imparcial un Laudo Arbitral justo y razonable basado en los hechos del caso y los términos del contrato, de conformidad con la ley, y con referencia a las prácticas internacionales"(énfasis agregado), declaró que resolverá la disputa "por prácticas internacionales", más precisamente de acuerdo con las disposiciones relevantes de los principios de Unidroit que en su opinión "representaba los principios generales de las leyes contractuales".

En esta misma base de datos encontramos varios casos similares. Tales como: Arbitraje ad hoc San José de Costa Rica (2001); Corte internacional de Arbitraje de la CPI 11018 (2002); Tribunal de Arbitraje Internacional de la Cámara de Comercio e Industria de la Federación de Rusia (2002); Corte Internacional de Arbitraje de la CPI 12040 ( 2003); Corte Internacional de Arbitraje de la CPI 11575 (2003); Corte Internacional de Arbitraje de la CPI 12111 (2003); Corte Internacional de Arbitraje de la CPI 12111 (2003); y Corte Internacional de Arbitraje de la CPI 13012 (2004). Estos casos mencionan a los principios Unidroit como expresión de la lex mercatoria, decisiones que tienen como sustento su preámbulo, el cual menciona que estos tienen cabida cuando las partes hayan acordado que su contrato se rija por los principios generales del derecho, la lex mercatoria o expresiones semejantes. 
Ahora bien, de estas circunstancias nace el fundamento para presentar una segunda aproximación a la posibilidad de aplicación de las instituciones de los principios Unidroit en nuestro sistema jurídico, aún sobre contratos locales. Todo ello a partir del estudio del sistema de fuentes mercantil colombiano.

En tal sentido, el Código de Comercio (1971) en el artículo 7 señala que:

Los tratados o convenciones internacionales de comercio no ratificados por Colombia, la costumbre mercantil internacional que reúna las condiciones del artículo 3, así como los principios generales del derecho comercial, podrán aplicarse a las cuestiones mercantiles que no puedan resolverse conforme a las reglas precedentes.

De esta manera, la costumbre mercantil internacional -y como integrante de esta tendríamos a los principios Unidroit- se constituye en fuente material o auxiliar del derecho comercial. Entre sus funciones está la de servir de criterio hermenéutico sobre el sentido y alcance de las fuentes formales, además, sobre esta se puede apoyar el operador jurídico a la hora de interpretar y aplicar la ley comercial nacional y, adicionalmente, puede servir de inspiración al legislador mercantil para la creación de nuevas normas comerciales en el futuro.

En este sentido, en Laudo Arbitral 8540 (1996) de la Corte Internacional de Arbitraje de la CPI, el tribunal arbitral manifiesta que:

Habiendo descubierto, sin embargo, después de la debida consideración del registro completo, que la ley aplicable del [acuerdo] es la ley del Estado de Nueva York, decidimos buscar principios generales solo para comparar la conclusión que resulta de la aplicación de la ley apropiada con la conclusión que se obtendría si el Tribunal aplicara estos principios generales. Al determinar el contenido de estos principios generales, nos sentimos totalmente justificados al referirnos a los principios de Unidroit.

En esta misma dirección, en resumen de arbitraje ad hoc (2020), de la página Unilex, se menciona que:

El contrato contenía una cláusula de elección de ley a favor de la legislación interna del Estado en cuestión. Sin embargo, el tribunal determinó que esta ley interna aún no se había desarrollado completamente después del cambio a una economía de mercado y contenía una serie de lagunas y ambigüedades que influían en la disputa. En consecuencia, el tribunal arbitral determinó que la legislación interna de ese Estado debería complementarse teniendo en cuenta especialmente los Artículos 1.4, 6.2.2-6.2.3 y 7.1.7 de los principios de Unidroit.

El planteamiento anterior, se refuerza con el hecho de que el artículo 5 del Código de Comercio (1971), al establecer las funciones de la costumbre mercantil, no distingue el tipo de costumbre al cual se dirige esta norma, por lo que son funciones que también competen a la costumbre mercantil internacional y en nuestro caso a los principios Unidroit. 
Al respecto, dice el artículo 5 del Código de Comercio (1971): "Las costumbres mercantiles servirán, además, para determinar el sentido de las palabras o frases técnicas del comercio, y para interpretar los actos y convenios mercantiles".

En este contexto, León y López (2016) plantean que:

Adicionalmente, se comienzan a vislumbrar normas en sentido material que reconocen ciertos aspectos de la nueva lex mercatoria, como la manera más adecuada para reglamentar conductas comerciales, cuando existen negocios que involucran factores tanto internacionales como internos [...]. Pero quizá el más importante avance en la materia se encuentra contenido en el reconocimiento de sus principios en los laudos arbitrales y la justicia nacional.

Es en estos fallos donde en realidad aparece la nueva lex mercatoria en todo su esplendor como un sistema adicional a la normativa interna, el cual permite regular no solamente contratos, sino que faculta a los jueces y árbitros para tener en ella una guía que permita integrar e interpretar las disposiciones de las partes. (p. 142)

En jurisprudencia de la Corte Suprema de Justicia del 21 de febrero del año 2012, esta corporación se refirió a la nueva lex mercatoria y, particularmente, a los principios Unidroit, como un instrumento al cual los jueces pueden acudir para interpretar el sistema legal interno. Al respecto cita la Corte:

Los principios, simbolizan el esfuerzo significativo de las naciones para armonizar y unificar disimiles culturas jurídicas, patentizan la aproximación al uniforme entendimiento contemporáneo de las relaciones jurídicas contractuales, superan las incertidumbres sobre la ley aplicable al contrato, los conflictos, antinomias, incoherencias, insuficiencia, ambigüedad u oscuridad de las normas locales al respecto [...], y el juzgador en su discreta labor hermenéutica de la ley o del acto dispositivo, podrá remitirse a ellos para interpretar e integrar instrumentos internacionales y preceptos legales internos. (Sentencia 2006-00537/12, 2012)

En línea con lo anterior, la Corte Constitucional en la Sentencia C-1008/10 (2010) analizó la constitucionalidad del artículo 1616 del Código civil (1873), para lo cual tuvo en cuenta normativas de derecho comercial internacional como los principios Unidroit. Así manifestó dicha corporación:

De lo anterior se sigue que en el ordenamiento legal colombiano la responsabilidad civil contractual continúa atada a la noción de culpa, |...|. Expresión de ello es el artículo 1616 del Código Civil, objeto de análisis de constitucionalidad. Esta concepción no resulta extraña al ordenamiento jurídico internacional, como quiera que referentes normativos como la Convención de Viena de 1980 y los principios sobre Contratos de la Unidroit, acogen el criterio de la previsión y la previsibilidad de la lesión, como baremo del monto de los perjuicios.

De esta manera, al juzgador para hacer frente a eventuales desequilibrios prestacionales, le resultaría jurídicamente viable acudir a los principios Unidroit para aplicar al caso esta institución y reestablecer el equilibrio prestacional desdibujado. En otras 
palabras, en una situación de abuso por excesiva desproporción, que no encaje dentro de los parámetros de lesión enorme que nuestro sistema jurídico interno reglamenta, es jurídicamente viable acudir a los principios Unidroit.

Esta es una posición racorde con la búsqueda de la armonización entre los sistemas mercantiles nacionales y los diversos instrumentos de lex mercatoria, en aras de la consolidación de un orden jurídico unitario de carácter mercantil, que responda eficazmente a las necesidades de regulación. No solamente de los negocios jurídicos internacionales, sino también de los nacionales o internos.

En esta línea, afirma Oppetit (2006):

La autonomía de los diversos modos de creación del derecho, igualmente aptos para conferir la juridicidad, no implica ni la separación ni la subordinación entre los distintos sistemas de normas, sino más bien, su armonía y su coherencia, lo cual no impide, de ningún modo, el reconocimiento de la preeminencia de ciertas normas o de ciertos principios. (p. 212)

\section{CONCLUSIONES}

Nuestro sistema de fuentes mercantil permite que instituciones contenidas en instrumentos de derecho comercial internacional tengan aplicación dentro del ámbito de los negocios jurídicos internos, en beneficio no solamente de la armonización de nuestra legislación privada con las prácticas jurídicas internacionales, sino también de la satisfacción de la justicia contractual. Dichos instrumentos son tales como, la excesiva desproporción y la excesiva onerosidad, regulados en los principios Unidroit,

Si bien nuestro régimen de derecho privado consagra figuras para el tratamiento del desequilibrio prestacional, su regulación resulta mucho más incipiente con relación a la que los principios Unidroit tiene frente a estas mismas circunstancias. Por esta razón, resulta plausible la aplicación de este instrumento internacional a los contratos comerciales domésticos, entre otras razones, porque son los mismos principios Unidroit los que en su preámbulo permiten expandir su margen de acción para servir como modelos de complemento o criterios de interpretación de los sistemas jurídicos locales.

Tanto la excesiva desproporción como la excesiva onerosidad (hardship), persiguen el restablecimiento del equilibrio prestacional, el cual se vio afectado en momentos diferentes del iter contractus. Para lo cual, dichos institutos se sustentan en la equidad, y en la buena fe de los contratantes, como los llamados en primera instancia a corregir dicha circunstancia.

Existen diversos pronunciamientos jurisprudenciales tanto de la justicia arbitral como de la justicia ordinaria, nacional e internacional, que le dan cabida a los principios Unidroit, como manifestación expresa de la nueva lex mercatoria. En este sentido, como 
criterio hermenéutico e integrador de las diversas normas jurídicas no solamente de carácter internacional, sino también de carácter interno o local.

Si bien los principios Unidroit en sus inicios fueron pensados como un mecanismo armonizador de la regulación sustancial aplicable a los contratos comerciales internacionales, hoy en día, en la práctica arbitral y jurisprudencial, estos se reflejan y se usan como normativa integradora y complementaria de los derechos positivos nacionales.

\section{REFERENCIAS}

Aljure, A. (2011). El contrato internacional. Legis.

Álvarez, A. (2009). Lesión enorme. En M. Castro (coord.). Derecho de las obligaciones. Tomo I (pp. 601622). Temis.

Arbitraje Internacional. (1996, 4 de septiembre). Laudo Arbitral 8540. Corte Internacional de Arbitraje de la CPI.

Arbitraje Internacional. (1996, 5 de junio). Laudo Arbitral 7375. Corte Internacional de Arbitraje de la CPI.

Cadena, W.R. (2006). Impacto en Colombia de la lex mercatoria. Revista Civilizar: ciencias sociales y humanas, 6(11), 19-39. https://doi.org/10.22518/16578953.755

Calderón, E. (2018). Los Incoterms como instrumento de derecho suave (soft law). Revista E-mercatoria. 17(1), 47-85. https://doi.org/10.18601/16923960.v17n1.02

Centro de Arbitraje de México, CAM. (2006, 30 de noviembre). Laudo Arbitral. Centro de Arbitraje de México. http://www.unilex.info/case.cfm?id=1149

Centro de Arbitraje y Conciliación. (2002, 22 de agosto). Laudo Arbitral. Centro de Arbitraje de la Cámara de Comercio de Bogotá.

Código de Comercio. (2019) 41 ed. Legis

Comisión de Arbitraje comercial y Económico Internacional de China (Cietac). (2016, 31 de octubre). Laudo Arbitral. Comisión de Arbitraje comercial y Económico Internacional de China. http://www. unilex.info/principles/case/2232

Congreso de Colombia. (1999, 4 de agosto). Ley 518 de 1999. Por medio de la cual se aprueba la "Convención de las Naciones Unidas sobre los contratos de compraventa internacional de mercaderías". Hecha en Viena el 11 de abril de 1980. Diario Oficial n. ${ }^{\circ}$ 43.656. http://www.secretariasenado.gov.co/senado/basedoc/ ley_0518_1999.html

Congreso de los Estados Unidos de Colombia. (1873, 26 de mayo). Ley 84 de 1873. Código civil de los Estados Unidos de Colombia. Diario Oficial no. 2867. http://bit.ly/2Ny4HA0

Corte Constitucional. (2010, 9 de diciembre). Sentencia C-1008/10 (Luis Ernesto Vargas Silva, M.P.). https://bit.ly/32V0JK5

Corte Internacional de Arbitraje. (1996, 4 de septiembre). Laudo Arbitral de la Corte Internacional de Arbitraje de la CPI. 4 de septiembre de 1996.

Corte Suprema de Justicia, Sala de Casación Civil. (2012, 21 de febrero). Sentencia 2006-00537/12 (William Namén Vargas, M.P.). https://bit.ly/3f6XcgG

Espinosa, L. (2010). ¿Cuál es la eficacia que le ha reconocido la corte constitucional colombiana al principio de autonomía de la voluntad privada consagrado en los instrumentos de carácter 
internacional incorporados al sistema jurídico colombiano? En J. Oviedo (coord.). Obligaciones y contratos en el derecho contemporáneo (pp. 421-529). Dike.

Fernández, J. C. (2004). Lex mercatoria y autonomía conflictual en la contratación transnacional. Anuario Español de Derecho internacional Privado, IV , 35-78. https://eprints.ucm.es/id/eprint/6964/

Franco, A. (2013). La excesiva onerosidad sobrevenida en la contratación mercantil: una aproximación desde la perspectiva de la jurisdicción civil en Colombia. En S. Sotomonte e I. Ortiz (coords.). Del derecho comercial al derecho del mercado (pp. 439 474). Universidad Externado.

León, E. (2014). Los principios de Unidroit. Como recurso de interpretación contractual en el derecho colombiano. Legis.

León, E. y López, Y. (2016). Derecho mercantil consuetudinario. Legis.

Mantilla, F y Ternera, F (2008). Breves comentarios sobre la revisión judicial del contrato. En F. Mantilla y F. Ternera (coords.). Los contratos en el derecho privado (pp. 319-324). Legis.

Morles, A. (2010). La revisión del contrato mercantil frente a la crisis económica mundial de 2009. En J. Gabino, M. Navas y Y. Alarcon (eds.). Realidades y tendencias del derecho en el siglo XXI. Tomo IV (pp. 347-381). Temis.

Oppetit, B. (2006). Teoría del arbitraje. Legis.

Organización de las Naciones Unidas. Convención de las Naciones Unidas sobre los contratos de compraventa internacional de mercaderías. (1980). https://uncitral.un.org/es/texts/salegoods/ conventions/sale_of_goods/cisg

Oviedo, J. (2009). Estudios de derecho mercantil internacional. Ibañez.

Polidura, A. (2017). El restablecimiento de las condiciones contractuales frente al desequilibrio sobreviniente en el derecho privado colombiano. Revista de derecho privado, 57, 1-36. https://bit. ly/3eYKbaR

Presidencia de la República. (1971, 27 de marzo). Decreto 410 de 1971. Código de Comercio. Diario Oficial n. 33339 . http://www.secretariasenado.gov.co/senado/basedoc/codigo_comercio.html

Principios Unidroit. (2010). Principios Unidroit sobre los contratos comerciales internacionales. https://www. internationalcontracts.net/documentos-derecho-internacional/Principios-UNIDROIT-sobreContratos-Comerciales-Internacionales.pdf

Rocha, L. S., y Da Luz, C. K. (2009). Lex Mercatoria and governance. The polycontexturality between law and state. Revista da Faculdade de Direito do Sul de Minas, 28, 105 126. https://www.academia. edu/36626193/LEX_MERCATORIA_AND_GOVERNANCE_THE_POLYCONTEXTURALITY_BETWEEN_ LAW_AND_STATE

Rodríguez, M. (2009). Introducción al Derecho Comercial Internacional. Universidad Externado.

Tobar, J. (2020). Los principios unidroit. Fundamentos, practica y aplicaciones. Ibáñez.

Toro, J. (2019). La costumbre mercantil internacional. La lex mercatoria en la gobernanza global contemporánea. Revista foro del jurista. Costumbre mercantil, 35, 77-103. https://www.camaramedellin. com.co/biblioteca/foro-del-jurista-n176-35-costumbre-mercantil

Tribunal de Distrito de los Estados Unidos, SD Florida. (2007, 30 de marzo). Sentencia 06-21088/07 (William M. Hoeveler, DJ Senior). http://www.unilex.info/principles/case/1528 
Tribunal Supremo Español (2014, 30 de junio). Sentencia 333/14 (Francisco Javier Orduña Moreno, M.P.). https://supremo.vlex.es/vid/-520648878

Unilex (2020). Laudo Arbitral Ad hoc. Unilex. http://www.unilex.info/principles/case/757

Unilex (2020). Unilex on Unidroit Principles y CISG International Case Law y Bibliography. http://www.unilex.info/

Unilex. (2020). Corte Internacional de Arbitraje de la CPI [Casos de los años 2002, 2003 y 2004]. http:// www.unilex.info/principles/cases/article/102/issue/1212

Vásquez, M.F. y Vidal, Álvaro. (2018). Diálogos entre la Convención sobre la Compraventa Internacional de Mercaderías (CISG) y la lex mercatoria. Revista de Derecho Privado, 34, 233-275. https://doi. org/10.18601/01234366.n34.08 